\title{
Simultaneous Determination of Some Biochemical Contents of Coffee Arabica (Coffea arabica L.) Varieties and Correlation with Organoleptic Cup Quality in Contrasting Altitudes in Southwest Ethiopia
}

\author{
Bealu Girma \\ Ethiopian Institute of Agricultural Research, Jimma Agricultural Research Center, Jimma, Ethiopia
}

\begin{abstract}
Coffee is one of the most important agricultural commodities. The objective of this study was to simultaneously determination the biochemical constituents (caffeine, chlorogenic and nicotinic acids) and correlation with organoleptic cup quality of commonly grown coffee Arabica varieties in contrasting altitude of Southwest Ethiopia. A rapid and validated HPLC Diode Array Detector method was used for the simultaneous determination of targeted analytse in green and roasted coffee beans. The moisture content and $\mathrm{pH}$ were recorded from $10.13 \pm 0.04$ to $12.49 \pm 0.08$ and $5.36 \pm 0.04$ to $5.81 \pm 0.04$ respectively. The results of the chemical analysis showed that caffeine content in green coffee varieties was ranged from $12.34 \pm 0.08 \mathrm{mg} / \mathrm{g}$ (high altitude) to $19.89 \pm 0.28 \mathrm{mg} / \mathrm{g}$ (low altitude), chlorogenic content was also recorded $27.17 \pm 0.38 \mathrm{mg} / \mathrm{g}$ (high altitude) to $39.18 \pm 0.24 \mathrm{mg} / \mathrm{g}$ (low altitude) and nicotinic acid was ranged from $7.13 \pm 0.52 \mathrm{mg} / \mathrm{g}$ (low altitude) to $10.16 \pm 0.75 \mathrm{mg} / \mathrm{g}$ (high altitude). The caffeine content in roasted coffee varieties was ranged from $13.93 \pm 0.29$ (high altitude) to $20.88 \pm 0.14 \mathrm{mg} / \mathrm{g}$ (low altitude) and chlorogenic content was recorded $8.56 \pm 0.02$ (high altitude) to $16.21 \pm 0.10 \mathrm{mg} / \mathrm{g}$ (low altitude) and nicotinic acid ranged from $8.76 \pm 0.11 \mathrm{mg} / \mathrm{g}$ (high altitude) to $6.34 \pm 0.031 \mathrm{mg} / \mathrm{g}$ (low altitude). A highly significant decrement was observed in chlorogenic acid content after roasting, as altitude increases the caffeine and chlorogenic acid decreased. In contrary, nicotinic acid increase as altitude increase in green coffee varieties. As can be concluded from the result, as altitude increases caffeine and chlorogenic acid decreases but nicotinic acid increase. The caffeine content in green beans was lower as compared to roasted beans; significant degradation of chlorogenic acid was observed after roasting beans of the same variety. There was a significant interaction between altitude and coffee varieties on chemical constituents of coffee. These chemical contents could be used for coffee discriminators of coffee varieties and different altitudes. A highly significant correlation was also observed between biochemical contents and cup quality evaluation with altitude.
\end{abstract}

Keywords: key word Altitude, Coffee, Varieties'

DOI: $10.7176 / \mathrm{FSQM} / 93-03$

Publication date: January $31^{\text {st }} 2020$

\section{Introduction}

Coffee (Coffea L.) is the world's favorite beverage and the second-most traded commodity after oil (Davis, 2012).The coffee bean is obtained from the fruit of the coffee plant, a small evergreen shrub belonging to the genus Coffea, family Rubiaceae (Davis et al., 2006).Only two species namely arabica (Coffea arabica L.) and robusta (CoffeacanephoraPierre) are under commercial cultivation (Lashermes et al., 1999; Anthony et al., 2002).The value of coffee for producers' country about $\$ 14$ billion annual income generator and more than 18 countries, including Ethiopia, export coffee product to more than 165 countries providing a livelihood for an estimate of 100 million people around the world (ICO, 2001). Ethiopia is currently producing an estimated 8.1 million bags that would rank the country as Africa's largest coffee producer, fifth and tenth Arabica coffee producer and export worldwide respectively (ICO, 2013). Coffee is one of the major sources of export in the Ethiopian economy as it contributes $25-30 \%$ of Ethiopia's total export earnings (Abu Tefera, 2015).Beverage quality often referred to as drinking quality or liquor quality, is an important attribute of coffee (Muschler, 2001; Agwanda et al., 2003) and acts as a yardstick for price determination (Agwanda et al., 2003).Coffee beverage quality is based on the characterization of a large number of factors including taste and aroma. These factors are related to the biochemical content of roasted beans. A thousand compounds, appearing during roasting, are involved in coffee beverage quality. These compounds rise from a smaller number of biochemical compounds present in green beans. Their presence could have a favorable effect on the coffee beverage quality, as for trigonelline and sugars, or an unfavorable one, as for chlorogenic acids and caffeine (Clifford, 1985; Macrae, 1985). Beverage quality assessment is done organoleptically by trained coffee tasters (Van der Vossen, 1985; Agwanda, 1999) and Kathurima et al., 2010) recommended this method as sufficiently reliable for use as a basis of selection in quality improvement programs.

However, coffee quality results from interaction among many different factors including genotype $(\mathrm{G})$ and environment (E) (Muschler, 2001; Sunarharum, Williams, \& Smyth, 2014). Consumers of high-quality coffee may exercise a preference for genotype with the labeling of species (e.g. arabica) or environment of production (usually 
country) (Ky et al., 2001; Silvarolla, Mazzafera, \& Fazuoli, 2004). Environment factors such as shade and high altitude have been observed to improve coffee quality (Joet et al., 2010). Diversity of coffee quality due to genotype and environment, result from influences on the biochemical components of the coffee bean accumulated during seed development (Joet et al., 2010).

A lot of work has been done in attempting to understand the biochemical composition of green and roasted coffee beans and its effect on cup quality (Ky et al., 2001; Decazy et al., 2003; Bertrand et al., 2006; Farah et al., 2006; Kathurima et al., 2010; Tessema et al., 2011). Despite this, the specific contribution of evaluated biochemical traits to the final cup quality remains largely unknown. Kathurima et al. (2010) noted that there is a missing link between biochemical assessment studies and the genetic improvement of coffee. They noted that more progress would be expected if biochemical studies are integrated at the early stages of coffee improvement. Coffee quality is the result of complex interactions between the environment, the imposed management regime, and the plant. In coffee beans, the biochemical composition appears to be influenced by both genetic factors (Montagnon et al., 1998) and plant growth conditions (Viani, 2001; Leroy et al., 2006).

However, Southwestern Ethiopia is the natural habitat and the primary center of diversity of Coffea arabica (Meyer, 1965).The study was carried out to determine the beverage quality characteristics and biochemical constituents (caffeine, chlorogenic and nicotinic acid) of 12 coffee samples grown in contrasting altitudes in Southwest Ethiopia and identify discriminators of coffee quality.

\section{Materials and methods}

\section{Description of the study areas}

The study was carried out from November 2017 to August 2018. Coffee bean samples were collected from November to December 2017 in three different altitudes in Gera Agricultural Research Sub-Center (altitude:-19401960 m), Jimma Agricultural Research Center (altitude:-1754-1765 m) in Jimma Zone, Oromiya Regional State and Teppi Agricultural Research Center (altitude:-1200-1220 m) in State of Southwest Nation and Nationalities Peoples of Ethiopia (SNNPE) Region. Details of the sampling sites are presented in Table 1.

Table 1: Geographic location and biophysical data of the study areas in Southwest Ethiopia

\begin{tabular}{|llll|}
\hline Location & Highland (Gera) & Midland (Jimma) & Lowland (Teppi) \\
\hline Region & Oromia & Oromia & SNNPE \\
Altitude (m.a.s.l) & $1940-1960$ & $1750-1775$ & $1100-1200$ \\
Mean temperature $\left({ }^{\circ} \mathrm{C}\right)$ & $19-25$ & $20.5-27$ & $25-30$ \\
Rain fall in (mm) & $1880-2080$ & $1525-2000$ & $800-2000$ \\
Latitude/ Longitude & $6^{\circ} 30^{\prime} \mathrm{N}$ and $32^{\circ} 15^{\prime} \mathrm{E}$ & $7^{\circ} 40^{\prime} \mathrm{N}$ and $36^{\circ} 50^{\prime} \mathrm{E}$ & $9^{\circ} 08^{\prime} \mathrm{N}$ and $37^{\circ} 13^{\prime} \mathrm{E}$ \\
\hline
\end{tabular}

m.a.s.l $=$ meters above sea level

\section{Moisture content}

Moisture content was determined according to AOAC procedures (1995). Full matured coffee samples were pulped using single disc manual pulpier beans from the skin and pulp. It was determined by the coffee sample was weighed $(\mathrm{g})$ and recorded. The green coffee sample was dried in a dry an oven to a constant weight (100 beans), at $105^{\circ} \mathrm{C}$ for $24 \mathrm{hrs}$ and each sample was cooled and the weight (g) was taken. According to Adnan, et al., (2017) the percentage of moisture content was calculated. The moisture content of the parchment coffee was measured by moisture tester maintain the moisture level from 10.5-11.0\% (Sultan et al., 2014).

\section{pH}

The $\mathrm{pH}$ was measured according to Natalina et al., 2013 at $25^{\circ} \mathrm{C}$, after calibration of the electrode with $\mathrm{pH} 4.0,7.0$ and 10.0 buffer solutions. Ground green coffee $(10 \mathrm{~g} \pm 0.1 \mathrm{~g})$ was mixed with water $(200 \mathrm{~mL})$ and boiled for 5 min then cooled at room temperature, and the weight was adjusted by adding water. After filtration with a Whitman No. 1 filter, the $\mathrm{pH}$ of the filtrate was measured at room temperature.

\section{Roasting and sensory evaluation}

Physical and coffee cup quality analysis was carried out at Jimma Agricultural Research Center. According to Navarra, et al., 2017 procedures, for the analysis $350 \mathrm{~g}$ of each coffee sample was used out of which $200 \mathrm{~g}$ roasted at $160-200^{\circ} \mathrm{C}$ for $8 \mathrm{~min}$ using a roasting machine and $150 \mathrm{~g}$ was used for green coffee evaluation. The roasted beans were tipped out into a cooling tray and rapidly cooled by blowing cold air through the beans for four min and then ground with coffee was grinding machine. $13.75 \mathrm{~g}$ of ground coffee was diluted in $250 \mathrm{~mL}$ hot water $\left(93^{\circ} \mathrm{C}\right)$ to prepare an infusion (Navarra, et al., 2017). The coffee variety samples and their replicates were arranged at random and the cup quality attributes aromatic quality, aromatic intensity, acidity, body, flavor and overall cup quality was scored using scales ranging from 0 to 10 and 0 to 5 . Three cups of brewed coffee of each coffee sample were prepared for analysis and a team of three professional cuppers, from Jimma Agricultural Research Center, was taste and given a score for each of the three cups. Each panelist was given independent judgment for each 
sample unit of the treatment. Finally, the average results of all panelists were used for data analysis (Sultan et al., 2014).

Chemical analysis of, caffeine, chlorogenic and nicotinic acids Sample preparation for HPLC analysis

Coffee bean sample of each variety was prepared based on the method reported by Alves, et al., 2006. Accordingly, $0.5 \mathrm{~g}$ of roasted or raw ground coffee sample was extracted with $30 \mathrm{~mL}$ of solutions (HPLC grades water/Acetonitrile $(95: 5 \mathrm{v} / \mathrm{v})$ was added and allowed to boil in water bath in $80{ }^{\circ} \mathrm{C}$ for $10 \mathrm{~min}$, and was filtered with Whitman No.1 (7mm diameter) in to $100 \mathrm{~mL}$ flask. An aliquot $(5 \mathrm{ml})$ of the filtrate was transferred to a volumetric flask $(25 \mathrm{~mL})$, and the volume was made up with the extraction solution (HPLC grades water/Acetonitrile $(95: 5 \mathrm{v} / \mathrm{v})$. The final extraction was filtered with Whitman No.1 (4.5 mm diameter) and was added to vials injected directly into the HPLC-DAD chromatography. The HPLC conditions were adopted by Alves, et al., 2006. The separation was achieved a Spherisorb ODS-1 column $(150 \mathrm{~mm} \times 4.6 \mathrm{~mm} ; 5 \mu \mathrm{m})$ (England, with HPLC grade) was employed. An isocratic elution of acetic acid $/ \mathrm{H}_{2} \mathrm{O}(5: 95 \mathrm{v} / \mathrm{v})(\mathrm{A})$, and (B) acetonitrile was used until the end $10 \mathrm{~min}$, injection volume $20 \mu \mathrm{L}$, a column temperature of $30^{\circ} \mathrm{C}$ at a flow rate of $1.0 \mathrm{~mL} \mathrm{~min}^{-1} \mathrm{was}$ used.

\section{Data to be collected and analysis}

Raw and cup coffee quality such as moisture content, $\mathrm{pH}$, shape and make, color, aromatic intensity, aromatic quality, acidity, astringency, body, bitterness, flavor and overall quality and also caffeine, chlorogenic and nicotinic acid data were collected. Various descriptive statistical procedures (mean, percent relative standard deviation, linear regression and correlation analysis) and ANOVA was utilized in this study. All the descriptive statistical procedures SAS 9.0 were used and data that were described in samples of the coffee beans were reported as the mean $\pm \mathrm{SD}$ of measurements. Linear regression and correlation analysis were performed for the calculation of slope $(\mathrm{m})$ and correlation coefficient $(\mathrm{R})$ of the regression line of each sample.

\section{Results and Discussions \\ Moisture content and $\mathrm{pH}$ of coffee varieties \\ Moisture content}

Moisture content is one of the most important quality parameters of green coffee beans. Most coffee importing and exporting countries consider the moisture content of green coffee beans as one of the quality parameters. According to Adnan, et al., (2017), the safety range for moisture content of coffee is $8.0-12.5 \%$, based on the fresh matter. In this study, the moisture contents of coffee varieties, which were cultivated in different altitudes, were evaluated (Table 2).

Table 2: Moisture contents of coffee varieties with altitudes

\begin{tabular}{lllll}
\hline $\begin{array}{l}\text { Coffee } \\
\text { varieties }\end{array}$ & Highland & Midland & Altitude & \\
\hline 74110 & $12.49 \pm 0.08$ & $12.34 \pm 0.10$ & $11.37 \pm 0.02$ & $12.08 \pm 0.07$ \\
7454 & $12.17 \pm 0.13$ & $12.42 \pm 0.08$ & $11.26 \pm 0.09$ & $11.97 \pm 0.08$ \\
7440 & $12.47 \pm 0.38$ & $12.40 \pm 0.05$ & $10.56 \pm 0.01$ & $11.89 \pm 0.15$ \\
74112 & $12.25 \pm 0.08$ & $12.15 \pm 0.09$ & $10.13 \pm 0.05$ & $11.53 \pm 0.04$ \\
Mean & $12.32 \pm 0.19$ & $12.40 \pm 0.04$ & $10.83 \pm 0.09$ & $11.87 \pm 0.09$ \\
CV & 2.89 & & &
\end{tabular}

It was observed moisture contents of green coffee varieties were varied from $12.17 \pm 0.13$ to $12.49 \pm 0.08$; $12.15 \pm 0.09$ to $12.42 \pm 0.08$ and $10.13 \pm 0.05$ to $11.37 \pm 0.02$ for high altitude, mid altitude, and low altitude, respectively. A statistical test, two ways ANOVA $(\mathrm{P}<0.05)$ showed the presence of significant interaction between coffee varieties and altitudes in terms of their moister contents (Appendix Table 1). The highest moisture content was observed in 74110 coffee varieties which were collected from highaltitude. The lowest moisture content was recorded for 74112 coffee variety collected from low-altitude. Generally, the moisture contents of coffee varieties exhibited decrements with altitudes. High-altitude coffee varieties have exhibited the higher moisture contents, than the similar coffee varieties from mid-altitude and low altitude; this could be attributed to the presence of relatively high temperate and wind flow rate at mid altitude and low altitude. The moisture contents of all the studied coffee varieties were in the recommended safe range, i.e., below $12.50 \%$, for importing or exporting coffee beans Adnan, et al., (2017).Moisture content outside the safety range impairs the bean quality and safety. Beans with a moisture content above $12.5 \%$ are not allowed to be shipped and traded since it facilitates fungal growth and mycotoxin production (e.g., ochratoxin A) that are risks to human health Adnan, et al., (2017). On the other hand, moisture content below $8 \%$ also causes shrunken beans and an unwanted appearance. 


\section{The $\mathbf{p H}$ of coffee varieties}

Table 3 shows the $\mathrm{pH}$ of green coffee varieties. The $\mathrm{pH}$ of green bean coffee varieties was varied from $5.36 \pm 0.04$ to 5.81 \pm 0.04 . A statistical test, two-way ANOVA $(\mathrm{P}<0.05)$ showed that there the existence of significant interaction between coffee varieties and altitude in $\mathrm{pH}$ contents of green beans (Appendix Table 2). The highest $\mathrm{pH}$ was observed green beans of variety 7440 , which was collected from the high altitude. Generally, for all coffee varieties the $\mathrm{pH}$ of highland greatest among midland and lowland coffee.

Table 3: $\mathrm{pH}$ of green coffee varieties

\begin{tabular}{lllll}
\hline $\begin{array}{l}\text { Coffee } \\
\text { varieties }\end{array}$ & Highland & Midland & Altitude & Lowland \\
\hline 74110 & $5.80 \pm 0.04$ & $5.78 \pm 0.03$ & $5.69 \pm 0.01$ & $5.75 \pm 0.09$ \\
7454 & $5.74 \pm 0.09$ & $5.68 \pm 0.09$ & $5.36 \pm 0.04$ & $5.59 \pm 0.09$ \\
7440 & $5.81 \pm 0.04$ & $5.58 \pm 0.14$ & $5.56 \pm 0.13$ & $5.65 \pm 0.06$ \\
74112 & $5.66 \pm 0.13$ & $5.63 \pm 0.05$ & $5.62 \pm 0.05$ & $5.63 \pm 0.19$ \\
Mean & $5.73 \pm 0.06$ & $5.67 \pm 0.06$ & $5.57 \pm 0.06$ & $5.66 \pm 0.14$ \\
CV & 0.85 & & & \\
\hline
\end{tabular}

Simultaneously determination of caffeine, chlorogenic and nicotinic acids contents of green coffee varieties Separation and determination of caffeine, chlorogenic acid and nicotinic acid were performed using HPLC-DAD by monitoring at various wavelengths including $272 \mathrm{~nm}$ (for caffeine), $320 \mathrm{~nm}$ (for chlorogenic acid), and $260 \mathrm{~nm}$ (for nicotinic acid).

Table 4: Concentrations ( $\mathrm{mg} / \mathrm{g}$ ) caffeine, chlorogenic and nicotinic acid in green coffee varieties grown in different altitudes of Southwest Ethiopia (Mean $\pm \mathrm{SD}, \mathrm{n}=4$ ).

\begin{tabular}{|l|c|c|c|c|}
\hline \multicolumn{2}{|c|}{ Treatments } & \multicolumn{3}{|c|}{ Green coffee beans sample } \\
\hline \multirow{3}{*}{$\begin{array}{l}\text { Gera } \\
\text { High Alt.) }\end{array}$} & Varieties & Caffeine & Chlorogenic & Nicotinic \\
\cline { 2 - 5 } & 74110 & $12.34 \pm 0.08$ & $29.72 \pm 0.71$ & $8.16 \pm 0.04$ \\
\cline { 2 - 5 } & 7454 & $13.58 \pm 0.15$ & $27.17 \pm 0.38$ & $10.16 \pm 0.75$ \\
\cline { 2 - 5 } & 7440 & $13.1 \pm 0.45$ & $30.40 \pm 1.44$ & $8.53 \pm 0.45$ \\
\cline { 2 - 5 } & 74112 & $13.3 \pm 0.77$ & $34.56 \pm 2.09$ & $8.08 \pm 0.16$ \\
\cline { 2 - 5 } & Mean & $13.08 \pm 0.63$ & $31.50 \pm 3.05$ & $8.73 \pm 1.12$ \\
\hline \multirow{3}{*}{ (Mimma } & 74110 & $14.51 \pm 0.08$ & $31.34 \pm 1.67$ & $8.15 \pm 0.19$ \\
\cline { 2 - 5 } & 7454 & $16.07 \pm 0.58$ & $33.85 \pm 2.26$ & $7.34 \pm 1.57$ \\
\cline { 2 - 5 } & 7440 & $13.83 \pm 0.54$ & $30.72 \pm 0.64$ & $7.87 \pm 0.49$ \\
\cline { 2 - 5 } & 74112 & $13.87 \pm 0.53$ & $34.62 \pm 0.07$ & $7.91 \pm 0.46$ \\
\hline Teppi & Mean & $14.48 \pm 1.34$ & $33.15 \pm 2.18$ & $8.25 \pm 0.27$ \\
\cline { 2 - 5 } (Low Alt.) & 74110 & $15.14 \pm 0.39$ & $32.16 \pm 2.11$ & $7.13 \pm 0.53$ \\
\cline { 2 - 5 } & 7454 & $19.89 \pm 0.29$ & $39.18 \pm 0.24$ & $7.54 \pm 0.71$ \\
\cline { 2 - 5 } & 7440 & $15.6 \pm 0.96$ & $32.06 \pm 1.76$ & $7.63 \pm 0.05$ \\
\cline { 2 - 5 } & 74112 & $15.67 \pm 0.33$ & $33.62 \pm 0.88$ & \\
\hline
\end{tabular}

\section{Caffeine}

Table 4 shows concentrations of caffeine in green coffee beans varieties collected from different altitudes. The caffeine content of green beans varieties was varied from $15.14-19.89 \mathrm{mg} / \mathrm{g}$ (lowland); $13.83-16.07 \mathrm{mg} / \mathrm{g}$ (midland) and $12.34-13.58 \mathrm{mg} / \mathrm{g}$ (highland). The lowest $(12.34 \pm 0.076) \mathrm{mg} / \mathrm{g}$ and highest $(19.89 \pm 0.288) \mathrm{mg} / \mathrm{g}$ caffeine concentrations were observed in coffee varieties 47110 (at highland) and 7454 (at lowland), respectively. Two-way ANOVA results indicated caffeine content of green coffee beans is significantly affected by coffee varieties and altitude $(\mathrm{P}<0.005)$ Appendix Table 3). (For all coffee varieties, the caffeine content of the lowland greater than midland and highland coffees. However, the obtained caffeine contents ranged from 12.34 to 19.89 $\mathrm{mg} / \mathrm{g}$. The results are in agreement with previous studies by Kassaye et al., 2016, Ky et al., 2001 and Bekele, 2005.

\section{Chlorogenic acid}

Chlorogenic acid is another important chemical for verification of coffee varieties. The influence of altitude on its concentrations in green coffee beans was investigated (Table 4). The concentrations of chlorogenic acid were ranged from $27.17 \pm 0.38$ to $34.56 \pm 2.09 \mathrm{mg} / \mathrm{g}$ (in highland); $30.72 \pm 0.64$ to $34.62 \pm 0.07 \mathrm{mg} / \mathrm{g}$ (in midland); and $32.06 \pm 1.755$ to $39.18 \pm 0.24 \mathrm{mg} / \mathrm{g}$ (in lowland) coffee varieties. The lowest and highest concentrations of the compound were both observed in the same variety (7454) collected from highland and lowland, respectively. Coffee variety, 7454 demonstrated variations of the concentrations of chlorogenic acid with altitude, whereas the remaining three varieties exhibited almost similar concentrations in all altitudes. The obtained results were similar 
to the studies reported by Kassaye et al., 2016 and Ky et al., 2001 and Bekele, 2005.

However, these values showed the effects of altitude and coffee varieties on the concentration of chlorogenic acids. That means the concentration of chlorogenic is influenced by both variations of the altitudes and coffee variety. Generally, according to the finding of this study, chlorogenic contents of green coffee beans follow similar trends as that of caffeine contents.

\section{Nicotinic acid}

The observed concentrations of nicotinic acid in green coffee varieties are presented in Table 4 . The nicotinic acid contents of green coffee varieties were varied from $7.13 \pm 0.53$ up to $8.25 \pm 0.27 \mathrm{mg} / \mathrm{g} ; 7.38 \pm 0.96$ up to $8.34 \pm 1.57$ $\mathrm{mg} / \mathrm{g}$; and $8.08 \pm 0.16$ up to $10.16 \pm 0.75 \mathrm{mg} / \mathrm{g}$ in lowland, midland and highland coffee varieties. The smallest and highest nicotinic acid contents were observed in the same coffee variety, 7454, collected from lowland and highland, respectively. Generally, in contrast to caffeine and chlorogenic acid, lowland coffee varieties contained the lowest concentrations of nicotinic acid than coffee varieties collected from Midland and lowland. Statistical evaluation using two-way ANOVA $(\mathrm{p}<0.05)$ revealed the presence of interaction between coffee varieties and altitude on nicotinic acid of contents green coffee beans (Appendix Table 4). Generally, in contrast to caffeine and chlorogenic acid, lowland coffee varieties contained the highest concentrations of nicotinic acid than coffee varieties collected from midland and lowland.

\section{Simultaneously determination of caffeine, chlorogenic, and nicotinic acid contents of roasted coffee varieties Caffeine}

The observed concentrations of caffeine in roasted coffee varieties collected from different altitudes are presented in Table 5. The caffeine content of roasted beans varieties were varied from $19.21 \pm 0.66-20.88 \pm 0.14 ; 14.21 \pm$ $0.71-18.62 \pm 0.47$; and $13.93 \pm 0.29-17.22 \pm 0.76 \mathrm{mg} / \mathrm{g}$ in coffee varieties of lowland; midland and highland, respectively. The lowest $(13.93 \pm 0.29)$ and highest $(20.88 \pm 0.14) \mathrm{mg} / \mathrm{g}$ caffeine concentrations were observed in coffee varieties 74112 (from the highland) and 7454 (from the lowland), respectively. For all coffee varieties, the concentrations of caffeine were reduced when the altitude increases and thus, the highest caffeine concentration was observed for each variety of coffee collected from the lowland. Two way ANOVA results $(\mathrm{P}<0.05)$ also confirmed the presence of interaction between coffee varieties and altitude on caffeine content in roasted beans (Appendix Table 5).

Table 5: Concentrations (mg/g) caffeine, chlorogenic and nicotinic acid in roasted coffee varieties grown in different altitudes of Southwest Ethiopia (Mean $\pm \mathrm{SD}, \mathrm{n}=4$ ).

\begin{tabular}{|c|c|c|c|c|}
\hline \multicolumn{2}{|c|}{ Treatments } & \multicolumn{3}{|c|}{ Green coffee beans sample } \\
\hline \multirow{6}{*}{$\begin{array}{l}\text { Gera } \\
\text { (High Alt.) }\end{array}$} & Varieties & Caffeine & Chlorogenic & Nicotinic \\
\hline & 74110 & $17.22 \pm 0.76$ & $11.48 \pm 0.46$ & $7.92 \pm 0.18$ \\
\hline & 7454 & $16.92 \pm 1.37$ & $8.56 \pm 0.02$ & $8.76 \pm 0.11$ \\
\hline & 7440 & $14.49 \pm 1.69$ & $8.77 \pm 0.38$ & $8.44 \pm 0.08$ \\
\hline & 74112 & $13.93 \pm 0.29$ & $12.59 \pm 0.21$ & $7.98 \pm 0.15$ \\
\hline & Mean & $15.99 \pm 2.19$ & $13.03 \pm 3.36$ & $7.84 \pm 0.69$ \\
\hline \multirow{5}{*}{$\begin{array}{l}\text { Jimma } \\
\text { (Mid Alt.) }\end{array}$} & 74110 & $18.62 \pm 0.47$ & $13.16 \pm 0.43$ & $7.74 \pm 0.45$ \\
\hline & 7454 & $17.72 \pm 1.46$ & $15.25 \pm 1.19$ & $7.98 \pm 0.69$ \\
\hline & 7440 & $16.55 \pm 0.39$ & $12.51 \pm 0.21$ & $7.23 \pm 0.33$ \\
\hline & 74112 & $14.21 \pm 0.71$ & $13.61 \pm 0.36$ & $6.66 \pm 0.03$ \\
\hline & Mean & $16.43 \pm 1.58$ & $12.02 \pm 2.49$ & $7.33 \pm 0.67$ \\
\hline \multirow{5}{*}{$\begin{array}{l}\text { Teppi } \\
\text { (Low Alt.) }\end{array}$} & 74110 & $20.28 \pm 0.63$ & $14.82 \pm 1.50$ & $7.74 \pm 0.35$ \\
\hline & 7454 & $20.88 \pm 0.14$ & $15.27 \pm 0.01$ & $7.69 \pm 0.46$ \\
\hline & 7440 & $20.54 \pm 0.09$ & $16.21 \pm 0.10$ & $7.67 \pm 0.05$ \\
\hline & 74112 & $19.21 \pm 0.66$ & $14.19 \pm 0.32$ & $7.07 \pm 0.70$ \\
\hline & Mean & $20.23 \pm 0.04$ & $14.05 \pm 1.31$ & $7.13 \pm 0.66$ \\
\hline
\end{tabular}

Generally, the caffeine contents of the studied roasted coffee varieties ranged from $13.93-20.88 \mathrm{mg} / \mathrm{g}$. For each variety, the observed concentration of caffeine in the roasted coffee was higher than the corresponding green coffee beans. Literature also indicated that roasted coffee has higher caffeine content than green coffee beans Kassaye et al., 2017 and Casal, et al., 2000.

\section{Chlorogenic acid}

The recorded chlorogenic acid concentrations in roasted coffee varieties are given in Table 5. The concentrations of chlorogenic acid were ranged from $8.56 \pm 0.021$ to $11.48 \pm 0.46 \mathrm{mg} / \mathrm{g} ; 12.51 \pm 0.21$ to $15.25 \pm 1.19 \mathrm{mg} / \mathrm{g}$; and $14.19 \pm 0.32$ to $16.21 \pm 0.10 \mathrm{mg} / \mathrm{g}$ for coffee varieties collected from highland, midland and lowland, respectively. For every coffee variety, the lowest and highest concentrations of the analytes were observed in highland and 
lowland, respectively. Two-way ANOVA $(\mathrm{P}<0.05)$ indicated the interaction between roasted coffee varieties and altitude on chlorogenic acid contents (Appendix Table 6). The chlorogenic acid content of roasted beans of varieties 7440 higher $(\mathrm{P}<0.05)(16.21 \pm 0.10)$ compared (mid-altitude) $(12.51 \pm 0.21) \mathrm{mg} / \mathrm{g}$ and high altitude $(8.77 \pm 0.38) \mathrm{mg} / \mathrm{g}$ (Table 5). The coffee variety $7454(8.56 \pm 0.02) \mathrm{mg} / \mathrm{g}$ at high altitude has the lowest chlorogenic acid content than other varieties. Generally, the chlorogenic acid contents of the studied coffee samples ranged from 8.56 to $16.21 \mathrm{mg} / \mathrm{g}$. As can be seen, irrespective of the variations of the altitude, roasted coffee varieties have lower chlorogenic contents than green coffee beans, indicating the possibility of transformation of the compound into other compounds Align and Sabally, 2013.It was also reported that chlorogenic acid is thermally unstable can be lost $60.9 \%$ and $96.5 \%$ after light and dark roasting Arabica coffee respectively Hiroshi et al., 2008. The presence of variation of concentrations of chlorogenic acid with the variation of altitudes as well as coffee varieties were also reported in the literature Kassaye et al., 2017 and Ky et al., 2001.

\section{Nicotinic Acid}

The observed concentrations of nicotinic acid in roasted coffee varieties are given in Table 5. The nicotinic acid contents of green coffee varieties were ranged from $6.55 \pm 0.33-7.55 \pm 0.34,6.66 \pm 0.03-7.98 \pm 0.69 \mathrm{mg} / \mathrm{g}$; and $7.92 \pm 0.18-8.76 \pm 0.11 \mathrm{mg} / \mathrm{g}$ in lowland, midland and highland coffee varieties. The smallest and highest nicotinic acid contents were observed in the coffee varieties, 7454 , and same variety collected from lowland and highland, respectively. Unlike caffeine and chlorogenic acid, lowland coffee varieties had the lowest concentrations of nicotinic acid than coffee varieties collected from midland and lowland. Statistical analysis using two-way ANOVA $(\mathrm{p}<0.05)$ revealed the presence of interaction between coffee varieties and altitude on nicotinic acid contents of roasted coffee beans (Appendix Table 7). Irrespective of their varieties and altitudes, roasted samples showed relatively lower concentrations of nicotinic acid than green coffee samples. But, the roasted 7440, which was collected from lowland, exhibited higher concentration nicotinic acid than its corresponding green coffee. The obtained results were agreed with previous literature findings Giovanni et al., 2014, Rafael et al., 2015.

\section{Raw and cup quality evaluation}

\section{Shape and make of raw coffee beans}

Shape and make is an important green bean physical characteristic of coffee. It affects the roasting process and subsequently reduces cup quality. The shape and make indicates the bean boldness and uniformity in a sample. Evaluated as very good, good, fairly good, mixed, and small and weighted accordingly (Abrar and Negussie, 2015).

Table 6 showed mean comparisons of coffee varieties and altitudes on the shape and make content with Mean $\pm \mathrm{SD}, \mathrm{N}=3$. According to two ANOVA showed, there was no significant interaction between coffee varieties and altitude on the shape and make $(\mathrm{p}<0.05)$ (Appendix Table 8). In mean comparison, coffee variety 74110 at high altitude had higher shape and make (12.51) compare to mid (12.16) and low altitude (12.07). Coffee variety 74112 at higher had (11.00) shape and make compared to mid and high altitude (Table 6).

Table 6: Mean comparison shape and make content in green coffee beans of some coffee varieties grown across three altitudes in southwest Ethiopia (with Mean $\pm \mathrm{SD}, \mathrm{n}=3$ ).

\begin{tabular}{|lllll|}
\hline Coffee & \multicolumn{4}{c|}{ Altitude } \\
\cline { 2 - 5 } varieties & Highland & Midland & Lowland & Mean \\
\hline 74110 & $12.51 \pm 0.51$ & $12.16 \pm 1.258$ & $11.52 \pm 1.20$ & $12.07 \pm 0.58$ \\
7454 & $12.52 \pm 0.53$ & $12.00 \pm 0.56$ & $11.52 \pm 1.20$ & $12.02 \pm 0.37$ \\
7440 & $11.17 \pm 1.26$ & $11.83 \pm 0.89$ & $12.56 \pm 1.53$ & $11.84 \pm 0.76$ \\
74112 & $11.00 \pm 0.01$ & $12.00 \pm 0.01$ & $11.88 \pm 0.77$ & $11.64 \pm 0.60$ \\
Mean & $11.81 \pm 0.96$ & $12.00 \pm 0.01$ & $11.87 \pm 0.76$ & $11.89 \pm 1.20$ \\
$\mathrm{CV}$ & 4.80 & & & \\
\hline \multicolumn{5}{r}{ Scale of Shape and make: - v. good=15; Good =12; Fair good=10; Average=8; Mixed $=6 ;$ Small $=4^{\prime \prime}$} \\
\hline
\end{tabular}

\section{Color}

It is another physical characteristic of coffee quality. It is evaluated as bluish, grayish, greenish, coated, faded, white, and weighted (Abrar and Negussie, 2015). Table 7 showed mean comparisons of coffee varieties and altitudes on the color content with Mean $\pm \mathrm{SD}, \mathrm{N}=3$. There was no significant interaction between coffee varieties and altitude on the color of roasted coffee beans $(\mathrm{p}<0.05)$ (two way ANOVA showed) (Appendix Table 9). In mean comparison, coffee variety 7454 at high altitude had higher color (13.52) compare to mid (11.50) and low altitude (11.38). Similarly coffee variety 74110 in high altitude had high (12.38) compared to mid (12.33) and low altitude (11.21). 7454 in high altitude had the highest (13.52) than the rest mid and high altitude. Coffee variety 7454 high altitudes had the lowest in color. 
Table 7: Mean comparison on color content in green coffee beans of some coffee varieties grown across three altitudes in southwest Ethiopia (with Mean \pm SD, $n=3$ ).

\begin{tabular}{|lllll|}
\hline \multirow{2}{*}{$\begin{array}{l}\text { Coffee } \\
\text { varieties }\end{array}$} & \multicolumn{4}{c|}{ Altitude } \\
\cline { 2 - 5 } & Highland & Midland & Lowland & Mean \\
74110 & $12.83 \pm 1.06$ & $12.23 \pm 1.20$ & $11.21 \pm 1.10$ & $12.11 \pm 0.93$ \\
7454 & $13.52 \pm 0.87$ & $11.50 \pm 0.50$ & $11.38 \pm 1.41$ & $12.16 \pm 1.60$ \\
74112 & $10.33 \pm 1.15$ & $11.0 \pm 1.01$ & $12.00 \pm 0.89$ & $11.10 \pm 1.31$ \\
Mean & $11.67 \pm 1.04$ & $13.19 \pm 0.98$ & $11.40 \pm 0.58$ & $12.12 \pm 1.15$ \\
CV & $12.11 \pm 1.29$ & $12.00 \pm 1.2$ & $11.50 \pm 0.29$ & $11.87 \pm 0.28$ \\
\hline
\end{tabular}

Scale of Color:-Bluish =15; Grayish =12; Greenish =10; Coated =8; Faded=6; White =4"

Color is the visual appearance of the brewed cup of coffee. Ones' aspect of visual appearance indicates color and the direct effect of caramelization power of the sugar beans based on roasting degree. The roasting degree also depends on the size and 'shape and make' of green coffee beans (Alemayehu, 2017).

\section{Aromatic Intensity}

Table 8 showed a mean comparison of coffee varieties and altitudes on Aromatic Intensity content with Mean \pm $\mathrm{SD}, \mathrm{N}=3$. Two-way ANOVA shows there was no significant interaction between coffee varieties and altitude on the aromatic intensity of roasted coffee beans $(\mathrm{p}<0.05)$ (Appendix Table 10). Coffee variety 74112 at high altitude had high aromatic intensity (4.33) (strong aromatic intensity) compared to mid (4.17) and low altitude (3.67) (Table 8).Similarly, coffee variety 74110 higher altitude had higher aromatic intensity (4.00) compared to mid (4.00) and low altitude (3.83).

Table 8: Mean comparison on aromatic intensity content in green coffee beans of some coffee varieties grown across three altitudes in southwest Ethiopia (with Mean $\pm \mathrm{SD}, \mathrm{n}=3$ ).

\begin{tabular}{|lllll|}
\hline Coffee & \multicolumn{4}{c|}{ Altitude } \\
\cline { 2 - 5 } varieties & Highland & Midland & Lowland & Mean \\
\hline 74110 & $4.00 \pm 1.00$ & $4.00 \pm 0.87$ & $3.83 \pm 1.04$ & $3.83 \pm 0.65$ \\
7454 & $3.50 \pm 0.50$ & $3.67 \pm 0.29$ & $3.67 \pm 0.29$ & $3.61 \pm 0.33$ \\
7440 & $3.83 \pm 1.04$ & $4.00 \pm 0.87$ & $4.00 \pm 1.00$ & $3.94 \pm 0.85$ \\
74112 & $4.33 \pm 0.58$ & $4.17 \pm 0.77$ & $3.67 \pm 0.29$ & $4.06 \pm 0.49$ \\
Mean & $3.83 \pm 0.29$ & $3.94 \pm 0.85$ & $3.67 \pm 0.29$ & $3.86 \pm 0.59$ \\
CV & 7.06 & & & \\
\hline
\end{tabular}

Scale of Aromatic intensity:-V. strong=5; strong=4; medium =3; light=2; V. light $=1 ;$ Nil $=0$

\section{Aromatic Quality}

It is sensation that is hard to separate from flavor. The aroma contributes to the flavors are discern on our palates. Subtle nuance, such as 'Floral' or 'winey' characteristics, are obtained from the aroma of brewed coffee (Abrar and Negussie, 2015).

Table 9 showed Mean comparison of coffee varieties and altitudes on aromatic quality with Mean $\pm S D, N=3$. Two-way ANOVA showed there was no significant interaction between coffee varieties and altitude on aromatic quality of roasted coffee beans $(\mathrm{p}<0.05)$ (Appendix Table 11). Coffee variety 7440 higher in high altitude (4.00) compared to mid-altitude (3.83). Coffee variety 7454 in mid-altitude had the lowest aromatic quality (Table 9).

Table 9 Mean comparison on aromatic quality content in green coffee beans of some coffee varieties grown across three altitudes in southwest Ethiopia (with Mean $\pm \mathrm{SD}, \mathrm{n}=3$ ).

\begin{tabular}{|lllll|}
\hline Coffee & \multicolumn{4}{c|}{ Altitude } \\
\cline { 2 - 5 } varieties & Highland & Midland & Lowland & Mean \\
\hline 74110 & $3.83 \pm 0.29$ & $3.67 \pm 0.29$ & $3.83 \pm 0.29$ & $3.78 \pm 0.26$ \\
7454 & $3.50 \pm 0.50$ & $3.17 \pm 0.29$ & $3.50 \pm 0.50$ & $3.38 \pm 0.56$ \\
7440 & $4.00 \pm 1.00$ & $3.83 \pm 1.04$ & $4.17 \pm 0.76$ & $4.00 \pm 0.83$ \\
74112 & $4.00 \pm 0.01$ & $4.00 \pm 0.87$ & $3.50 \pm 0.50$ & $3.83 \pm 0.56$ \\
Mean & $3.83 \pm 0.54$ & $3.66 \pm 0.69$ & $3.75 \pm 0.54$ & $3.75 \pm 0.8$ \\
CV & 11.84 & & & \\
\hline
\end{tabular}

Scale of Aromatic quality: - excellent $=5 ;$ v.good=4; $\operatorname{good}=3 ;$ regular $=2 ;$ Bad $=1 ;$ Nil $=0 "$

\section{Acidity}

Table 10 showed a mean comparison of coffee varieties and altitudes on acidity content with Mean $\pm \mathrm{SD}, \mathrm{N}=3$. Two-way ANOVA shows there was no significant interaction between coffee varieties and altitude on the acidity of roasted coffee beans $(\mathrm{p}<0.05)$ (Appendix Table 12). Coffee variety 74112 has higher in mid-altitude (7.50) as 
compared to low (7.17) and high altitude (7.0). Coffee variety 74110 had higher acidity content in low (7.83) altitude as compared to mid (6.50) and high altitude (7.00). Coffee variety 7440 had higher in the mid-latitude (7.00) as compared to high (6.50) and low altitude (6.83). The lowest in acidity content from the varieties was 74110 in mid-altitude (Table 10).

Table 10: Mean comparison on acidity content in green coffee beans of some coffee varieties grown across three altitudes in southwest Ethiopia (with Mean $\pm \mathrm{SD}, \mathrm{n}=3$ ).

\begin{tabular}{|lllll|}
\hline Coffee & \multicolumn{3}{c|}{ Altitude } \\
\cline { 2 - 5 } varieties & Highland & Midland & Lowland & Mean \\
\hline 74110 & $7.00 \pm 0.50$ & $6.50 \pm 0.50$ & $7.83 \pm 0.29$ & $7.11 \pm 0.70$ \\
7454 & $7.00 \pm 0.50$ & $7.00 \pm 0.50$ & $6.67 \pm 0.58$ & $6.89 \pm 0.49$ \\
7440 & $6.50 \pm 0.00$ & $7.00 \pm 0.00$ & $6.83 \pm 0.76$ & $6.78 \pm 0.44$ \\
74112 & $7.17 \pm 0.29$ & $7.50 \pm 0.87$ & $7.00 \pm 0.50$ & $7.22 \pm 0.57$ \\
Mean & $6.92 \pm 0.42$ & $7.00 \pm 0.60$ & $7.08 \pm 0.67$ & $7.00 \pm 0.56$ \\
CV & 7.06 & & & \\
\hline
\end{tabular}

Scale of Acidity Pointed =10; M. pointed=8; Medium =6; Light =4; Lacking=2;Nil=0"

Acidity indicates the bitter or acidic balance that a sweet caramelic after taste which could be affected by roast degree and phonology of coffee fruit that means shade may have indirect effect on coffee cup quality test (Alemayehu, 2017).

\section{Astringency}

Table 11 showed that mean comparison of coffee varieties and altitudes onAstringency content with Mean $\pm \mathrm{SD}$, $\mathrm{N}=3$. Two-way ANOVA shows there was no significant interaction between coffee varieties and altitude on astringency of roasted coffee beans $(\mathrm{p}<0.05)$ (Appendix Table 13). The coffee variety of 74110 had higher antigenicity (4.33) in low altitude as compared to mid (4.01) and low altitude (4.00). The coffee variety 7440 had lower in astringency in higher altitude (4.00) as compared to mid (4.16) and low altitude (4.17). The lowest astringency was observed at low altitude in 7454.variety (Table 10).

Table 11: Mean comparison on Astringency content in green coffee beans of some coffee varieties grown across three altitudes in southwest Ethiopia (with Mean $\pm \mathrm{SD}, \mathrm{n}=3$ ).

\begin{tabular}{|lllll|}
\hline \multirow{2}{*}{$\begin{array}{l}\text { Coffee } \\
\text { varieties }\end{array}$} & \multicolumn{4}{c|}{ Altitude } \\
\cline { 2 - 5 } & Highland & Midland & Lowland & Mean \\
74110 & $4.00 \pm 1.00$ & $4.01 \pm 1.00$ & $4.33 \pm 0.58$ & $4.11 \pm 0.60$ \\
7454 & $4.00 \pm 1.00$ & $4.00 \pm 0.76$ & $3.67 \pm 0.58$ & $3.89 \pm 0.78$ \\
74112 & $4.00 \pm 1.00$ & $4.16 \pm 0.76$ & $4.17 \pm 0.76$ & $4.11 \pm 0.74$ \\
Mean & $4.17 \pm 0.76$ & $4.16 \pm 0.76$ & $4.17 \pm 0.76$ & $4.17 \pm 0.66$ \\
CV & $4.04 \pm 0.81$ & $4.08 \pm 0.63$ & $4.08 \pm 0.63$ & $4.07 \pm 0.68$ \\
\hline
\end{tabular}

Scale of Astringency:-Nil =5; V.ligh $t=4 ;$ Light $=3 ;$ Medium $=2 ;$ Strong $=1 ;$ V.strong=0"

It is described complex sensation accompanied by shrinking, drawing or puckering mucosal surface in the mouth, produced by like tannins and sloe tannins (Abrar and Negussie, 2015). The higher content of astringency of the coffee beverage may be due to higher content of sucrose and chlorogenic acid in green coffee beans based on its size and ripping paired. This chlorogenic acid is reduced to organoleptic quality especially under unshaded beans than shaded ones (Morais et al., 2006).

\section{Bitterness}

Table 12 showed that mean comparison of coffee varieties and altitudes onBitterness content with Mean $\pm \mathrm{SD}$, $\mathrm{N}=3$. Two-way ANOVA showed there was no significant interaction between coffee varieties and altitude on the bitterness of roasted coffee beans $(\mathrm{P}<0.05)$ (Appendix Table 14).Coffee variety 74110 had higher in low altitude (4.17) as compared to mid (3.50) and higher (4.00) in bitterness content. Coffee variety 7440 had higher in midaltitude (4.33) as compared to high (3.33) and low altitude (4.17). coffee variety of 7440 in high altitude had the lowest in the high-altitude varieties (Table 12). 
Table 12: Mean comparison on Bitterness content in green coffee beans of some coffee varieties grown across three altitudes in southwest Ethiopia (with Mean $\pm \mathrm{SD}, \mathrm{n}=3$ ).

\begin{tabular}{|lllll|}
\hline Coffee & \multicolumn{4}{c|}{ Altitude } \\
\cline { 2 - 5 } varieties & Highland & Midland & Lowland & Mean \\
\hline 74110 & $4.00 \pm 1.00$ & $3.50 \pm 0.50$ & $4.17 \pm 0.76$ & $3.89 \pm 0.74$ \\
7454 & $4.00 \pm 0.87$ & $4.00 \pm 1.00$ & $3.33 \pm 0.58$ & $3.77 \pm 0.80$ \\
7440 & $3.33 \pm 0.58$ & $4.33 \pm 0.58$ & $4.17 \pm 0.76$ & $3.94 \pm 0.73$ \\
74112 & $4.00 \pm 1.00$ & $4.33 \pm 0.58$ & $4.00 \pm 0.00$ & $4.11 \pm 0.60$ \\
Mean & $3.83 \pm 0.81$ & $4.04 \pm 0.69$ & $3.92 \pm 0.63$ & $3.93 \pm 0.70$ \\
CV & 8.97 & & & \\
\hline
\end{tabular}

Scale of Bitterness:-Nil =5; V. light=4; Light=3; medium =2; Strong=1; V. strong=0"

Bitterness is the perception of coffee brew on the tongue of panelist during cup tasting. It is opposite to sweetness (Abrar and Negussie, 2015).

\section{Body}

Table 13 showed that mean comparison of coffee varieties and altitudes on Body content with Mean $\pm \mathrm{SD}$, $\mathrm{N}=3$. Two-way ANOVA showed there was no significant interaction between coffee varieties and altitude on body roasted coffee beans $(\mathrm{P}<0.05)$ (Appendix Table 15). Coffee variety 7440 had higher in low altitude (7.17) as compared to mid (7.00) and high altitude (6.83) in the body. Coffee variety 74112 had higher in low altitude (7.29) as compared to mid (7.00) and high altitude (7.13) in the body. The lowest body content was observed a coffee variety of 74110 in high altitude and 7440 of high-altitude coffee (6.38)(Table 13).

Table: 13 Mean comparison on Body content in green coffee beans of some coffee varieties grown across three altitudes in southwest Ethiopia (with Mean $\pm \mathrm{SD}, \mathrm{n}=3$ ).

\begin{tabular}{|lllll|}
\hline \multirow{2}{*}{$\begin{array}{l}\text { Coffee } \\
\text { varieties }\end{array}$} & Mighland & Midland & Lowland & Mean \\
\hline 74110 & $7.33 \pm 0.58$ & $6.83 \pm 0.29$ & $7.50 \pm 0.50$ & $7.22 \pm 0.51$ \\
7454 & $7.33 \pm 0.76$ & $7.00 \pm 0.50$ & $7.17 \pm 0.29$ & $7.17 \pm 0.50$ \\
7440 & $6.83 \pm 0.29$ & $7.00 \pm 0.50$ & $7.17 \pm 0.29$ & $7.00 \pm 0.35$ \\
74112 & $7.00 \pm 0.50$ & $7.17 \pm 0.76$ & $7.33 \pm 0.29$ & $7.17 \pm 0.50$ \\
Mean & $7.13 \pm 0.53$ & $7.00 \pm 0.48$ & $7.29 \pm 0.33$ & $7.13 \pm 0.46$ \\
CV & 5.96 & & & \\
\hline
\end{tabular}

Scale of Body (10\%):-Full =10, Medium full =8, medium=6, Light =4, V.light=2, Nil =0"

Available of body in a cup of coffee quality test indicates viscosity or thickness of coffee brewed. It is the physical property of beverage that the result in tactile sensations perceived on the skin in the mouth during and after ingestion based on beans quality (Alemayehu, 2017).

\section{Flavor}

Table 14 showed a mean comparison of coffee varieties and altitudes on flavor content with Mean $\pm \mathrm{SD}, \mathrm{N}=3$. Two-way ANOVA showed there was no significant interaction between coffee varieties and altitude on flavor roasted coffee beans $(\mathrm{p}<0.05)$ (Appendix Table 16). Coffee variety 74110 had higher in flavor content in low altitude (8.33) as compared to mid (7.83) and high altitude (8.00). Coffee variety 7440 had high in flavor content (8.00) in low altitude as compared to mid (7.83) and high altitude (7.50). The lowest flavor content was observed in 7440 coffee variety in high altitude (Table 14).

Table 14: Mean comparison on Flavor content in green coffee beans of some coffee varieties grown across three altitudes in southwest Ethiopia (with Mean $\pm \mathrm{SD}, \mathrm{n}=3$ ).

\begin{tabular}{|lllll|}
\hline Coffee & \multicolumn{3}{c|}{ Altitude } \\
\cline { 2 - 5 } varieties & Highland & Midland & Lowland & Mean \\
\hline 74110 & $8.00 \pm 0.50$ & $7.83 \pm 0.29$ & $8.33 \pm 0.29$ & $8.06 \pm 0.29$ \\
7454 & $8.00 \pm 0.50$ & $8.00 \pm 0.50$ & $7.67 \pm 0.29$ & $7.89 \pm 0.47$ \\
7440 & $7.50 \pm 0.00$ & $7.83 \pm 0.29$ & $8.00 \pm 0.50$ & $7.78 \pm 0.36$ \\
74112 & $8.17 \pm 0.29$ & $8.17 \pm 0.76$ & $7.83 \pm 0.58$ & $8.06 \pm 0.53$ \\
Mean & $7.92 \pm 0.42$ & $7.96 \pm 0.42$ & $7.96 \pm 0.58$ & $7.94 \pm 0.44$ \\
CV & 4.51 & & & \\
\hline
\end{tabular}

Scale of Flavor (10\%):- V.good=10, Good =8, Average =6, Fair =4, Bad=2, Nil=0”

Flavor is the simultaneous sensation in the test of aroma and taste. Coffee aroma is composed of the gaseous natural chemical components of roasted and brewed coffee beans, which escape as vapors after the coffee grounds are brewed. The perfume of the ground roasted coffee before water is added, it gives fragrance/aroma and one can smell the aroma, evaluate the body then perceive the taste and flavors (Muschler, 2001). 


\section{Overall cup quality}

Table 15 showed a mean comparison of coffee varieties and altitudes on overall cup quality content with Mean \pm $\mathrm{SD}, \mathrm{N}=3$. Two-way ANOVA showed there was no significant interaction between coffee varieties and altitude was observed in overall cup quality evaluation $(\mathrm{P}<0.05)$ (Appendix Table 17). Coffee variety 74110 had higher overall cup quality (8.50) as compared to mid (7.50) and low altitude. Coffee variety 74112 that grown in higher altitude had higher (8.33) overall quality as compared to mid (8.17) and low altitude (7.83). The lowest overall quality was observed in 7454 at higher altitude coffee variety. (Table 15)

Table 14 Mean comparison on overall cup quality content in green coffee beans of some coffee varieties grown across three altitudes in southwest Ethiopia (with Mean $\pm \mathrm{SD}, \mathrm{n}=3$ ).

\begin{tabular}{|lllll|}
\hline \multirow{2}{*}{$\begin{array}{l}\text { Coffee } \\
\text { varieties }\end{array}$} & Highland & Midland & Lowland & Mean \\
\hline 74110 & $8.50 \pm 0.00$ & $7.50 \pm 0.00$ & $8.17 \pm 0.29$ & $8.06 \pm 0.46$ \\
7454 & $7.67 \pm 0.29$ & $7.83 \pm 0.29$ & $8.00 \pm 0.50$ & $7.83 \pm 0.35$ \\
7440 & $7.83 \pm 0.29$ & $7.83 \pm 0.29$ & $7.67 \pm 0.29$ & $7.78 \pm 0.26$ \\
74112 & $7.83 \pm 0.58$ & $8.17 \pm 0.76$ & $8.33 \pm 0.58$ & $8.11 \pm 0.60$ \\
Mean & $7.96 \pm 0.45$ & $7.83 \pm 0.44$ & $8.04 \pm 0.45$ & $7.94 \pm 0.44$ \\
CV & 4.18 & & & \\
\hline
\end{tabular}

Scale of Overall cup quality (10\%): Excellent $=10$, v.good $=8$, Good $=6$, Regular $=4$, Bad $=2, \quad$ unacceptable $=0 "$

It can be recorded based on all the liquor quality attributes (intensity, aromatic quality, acidity, astringency, body, bitterness, and flavor) (Abrar and Negussie, 2015). In order to sum up all raw and cup quality evaluation were not a significant interaction between coffee varieties and altitude. But the data of physical and cup quality evaluation was considered according to in Ethiopian Commodity Exchange (ECX) grading system, the results to become more meaningful, and to quantify the quality of the coffee varieties.

\section{Raw and cup quality evaluation according to Ethiopian Commodity Exchange grading and evaluation} system.

There are two categories of coffee evaluation ways on the preliminary total quality, Physical (40/100) and preliminary cup quality (60/100) scores.

Table 16: Shows the coffee quality grading and evaluation of coffee varieties in contrasting altitude on the base of ECX was listed below.

\begin{tabular}{|c|c|c|c|c|c|c|}
\hline Altitude & Coffee varieties & $40 \%$ & $60 \%$ & $100 \%$ & Old ECX & Specialty \\
\hline \multirow[t]{4}{*}{ Highland } & 74110 & 34.5 & 46.3 & 80.8 & $\mathrm{G} 2$ & $\mathrm{Q} 2$ \\
\hline & 7454 & 35.3 & 45 & 80.3 & $\mathrm{G} 2$ & Q2 \\
\hline & 7440 & 30.5 & 43.8 & 74.3 & G3 & Commercial \\
\hline & 74112 & 31.5 & 46.7 & 78.2 & $\mathrm{G} 2$ & Commercial \\
\hline \multirow[t]{4}{*}{ Midland } & 74110 & 33.7 & 43.8 & 77.5 & $\mathrm{G} 2$ & Commercial \\
\hline & 7454 & 32.7 & 44.7 & 77.3 & $\mathrm{G} 2$ & Commercial \\
\hline & 7440 & 31.8 & 46 & 77.8 & $\mathrm{G} 2$ & Commercial \\
\hline & 74112 & 33.8 & 46.7 & 80.5 & $\mathrm{G} 2$ & Q2 \\
\hline \multirow[t]{4}{*}{ Lowland } & 74110 & 31.3 & 48 & 79.3 & G2 & Commercial \\
\hline & 7454 & 31.5 & 43.7 & 75.2 & $\mathrm{G} 2$ & Commercial \\
\hline & 7440 & 32.2 & 46.2 & 79.2 & $\mathrm{G} 2$ & Commercial \\
\hline & 74112 & 32 & 45.8 & 77.8 & G2 & Commercial \\
\hline
\end{tabular}

Grade 1=91-100, Grade $2=81-90$, Grade $3=71-80$, and grade 4= 70- 63,

Specialty $1=(Q 1)>85$, Specialty $2(Q 2)=80-84.75$ and Commercial $=(<80)$

Based on the ECX had five categories of coffee grading and evaluation, grade $1=91-100$, grade $2=81$ 90 , grade $3=71-80$, and grade $4=70-63$. If the scores of all samples were higher than 70 , cup quality for specialty coffee (coffees with the grade ranging from 1 to 3). Based on the total specialty score, coffee samples further grouped into a specialty1 (Q1) $>85$, specialty $2(\mathrm{Q} 2)$ 80-84.75 and a regular commercial coffee $(<80)$. (The new guideline) (ECX, 2015).

The first two of coffee varieties of 74110 and 7454 had qualified for specialty 2 (Q2),(80.8 and 80.3 respectively) from high altitude and also in old grading and evaluation (G2). New ECX grading and evaluation less than $(<\mathrm{Q} 2)(<80)$ are a commercial purpose. Coffee variety of 74112 had passed for the qualification of 2(Q2) in 80.5 from mid-altitude, also passed G2 of old grading and evaluation of ECX. All coffee varieties qualified for old grading of G2, except coffee variety 7440 in high altitude. Therefore all the coffee varieties were high grade qualified and in raw and cup evaluation and grading.

Raw and cup quality evaluation that includes shape and make, color, odor, aromatic intensity, aromatic quality, acidity, astringency, bitterness, body, flavor, and overall quality were evaluated by three professional cuppers $(\mathrm{Q}$ 
graders) in Jimma agriculture research center (JARC). Three measurements for each variety and all parameters was taken and quantified, analyzed and interpreted in the result part with two-way ANOVA that showed the interaction of altitude and varieties, but all were shown insignificant ( $p>0.05)$. To sum up, all the parameters were very good to interpret in Ethiopian commodity exchange evaluation that showed in Table 16. The results were supported by literature Kassaye et al., 2016. The biochemical contents and cup quality evaluation was correlation by Pearson Correlation and showed in the Table 17.

\section{Correlation between cup quality parameters and chemical contents of green and roasted coffee beans}

In this context, there was a correlation made between cup quality evaluation parameters and biochemical contents in green and roasted beans of coffee with the Pearson correlation coefficient method. From Pearson correlation, the moisture content has negatively $\left(\mathrm{r}=-6.10^{* *}\right)$ and a highly significant $(\mathrm{P}>0.001)$ correlated with caffeine in roasted coffee. The caffeine content in green coffee has positively $\left(\mathrm{r}=+0.78^{* *}\right)$ and highly significantly correlated with nicotinic acid of green coffee. The caffeine content in green coffee has positively $\left(\mathrm{r}=0.67^{* *}\right)$ and highly significantly $(\mathrm{P}>0.001)$ correlated with nicotinic acid of roasted coffee. The nicotinic acid content in green coffee has positively $\left(\mathrm{r}=+0.77^{* *}\right)$ and highly significantly $(\mathrm{P}>0.001)$ correlated with nicotinic acid content of roasted coffee. Raw quality has positively $\left(\mathrm{r}=0.87^{* *}\right)$ and highly significantly $(\mathrm{P}>0.001)$ correlated with overall quality of coffee. Cup quality has positively $\left(\mathrm{r}=0.68^{* *}\right)$ and highly significantly correlated to overall quality of coffee (Table 17).

The moisture content has negatively $\left(\mathrm{r}=-0.48^{*}\right)$ and significantly $(>0.05)$ correlated with caffeine green. The caffeine green positively $\left(\mathrm{r}=+0.58^{*}\right)$ and significantly $(\mathrm{p}>0.005)$ correlated with a chlorogenic acid content of green coffee. The moisture content has negatively $\left(r=-0.38^{*}\right)$ and significantly $(\mathrm{p}>0.005)$ correlated with nicotinic acid content of green coffee. The caffeine green content positively $\left(r=+0.56^{*}\right)$ and significantly $(p>0.005)$ correlated with caffeine roasted coffee. The caffeine green positively $(r=+0.59)$ and significantly $(p>0.05)$ correlated with chlorogenic acid content roasted coffee. The moister content negatively $(r=-0.48)$ and significantly $(p>0.005)$ correlated with nicotinic acid content of roasted coffee. The chlorogenic acid content of roasted coffee negatively $\left(\mathrm{r}=-0.35^{*}\right)$ and significantly $(\mathrm{p}>0.005)$ correlated with raw quality of the coffee (Table 17$)$.

Table 17: The Pearson correlation coefficients among physical, cup test and chemical constituents of coffee beans

\begin{tabular}{|c|c|c|c|c|c|c|c|c|c|c|c|}
\hline & Moisture & $\mathrm{pH}$ & $\begin{array}{l}\text { Caffeine } \\
\text { Green }\end{array}$ & $\begin{array}{l}\text { Chlorogenic } \\
\text { Green }\end{array}$ & $\begin{array}{l}\text { Nicotinic } \\
\text { Green }\end{array}$ & $\begin{array}{l}\text { Caffeine } \\
\text { Roast }\end{array}$ & $\begin{array}{l}\text { Chlorogenic } \\
\text { Roast }\end{array}$ & $\begin{array}{l}\text { Nicotinic } \\
\text { Roast }\end{array}$ & $\begin{array}{l}\text { Quality } \\
\text { Raw (40) } \\
\end{array}$ & $\begin{array}{l}\text { Quality } \\
\text { Cup (60) }\end{array}$ & $\begin{array}{l}\text { Quality } \\
\text { Overall }\end{array}$ \\
\hline Moisture & 1.00 & $0.138^{\text {ns }}$ & $-0.483^{*}$ & $-0.018^{\mathrm{ns}}$ & $-0.383^{*}$ & $-0.611 * *$ & $-0.183^{\mathrm{ns}}$ & $-0.484 *$ & $0.154^{\mathrm{ns}}$ & $-0.048^{\text {ns }}$ & $0.041^{\text {ns }}$ \\
\hline $\mathrm{pH}$ & & 1.00 & $0.115^{\text {ns }}$ & $0.295^{\mathrm{ns}}$ & $0.254^{\mathrm{ns}}$ & $0.1344^{\mathrm{ns}}$ & $0.255^{\mathrm{ns}}$ & $0.412 *$ & $-0.265^{\mathrm{ns}}$ & $0.065^{\mathrm{ns}}$ & $-0.084^{\mathrm{ns}}$ \\
\hline $\begin{array}{l}\text { Caffeine } \\
\text { Green }\end{array}$ & & & 1.00 & $0.584^{*}$ & $0.777^{* *}$ & $0.563^{*}$ & $0.343^{*}$ & $0.667^{* *}$ & $-0.229^{\mathrm{ns}}$ & $-0.178^{\mathrm{ns}}$ & $0.249^{\mathrm{ns}}$ \\
\hline CGA Green & & & & 1.00 & $0.552^{\mathrm{ns}}$ & $0.004^{\mathrm{ns}}$ & $0.587^{*}$ & $0.366^{\text {ns }}$ & $-0.226^{\mathrm{ns}}$ & $-0.023^{\mathrm{ns}}$ & $-0.138^{\mathrm{ns}}$ \\
\hline $\begin{array}{l}\text { Nicotinic } \\
\text { Green }\end{array}$ & & & & & 1.00 & $0.619^{\mathrm{ns}}$ & $0.219^{\mathrm{ns}}$ & $0.773^{* *}$ & $-0.128^{\mathrm{ns}}$ & $-0.104^{\mathrm{ns}}$ & $-0.142^{\mathrm{ns}}$ \\
\hline $\begin{array}{l}\text { Caffeine } \\
\text { Roast }\end{array}$ & & & & & & 1.00 & $0.134^{\mathrm{ns}}$ & $0.318^{\mathrm{ns}}$ & $-0.032^{\mathrm{ns}}$ & $0.087^{\mathrm{ns}}$ & $0.050^{\mathrm{ns}}$ \\
\hline $\begin{array}{l}\text { Chlorogenic } \\
\text { Roast }\end{array}$ & & & & & & & 1.00 & $0.318^{\mathrm{ns}}$ & $-0.352^{*}$ & $0.005^{\text {ns }}$ & $-0.172^{\mathrm{ns}}$ \\
\hline $\begin{array}{l}\text { Nicotinic } \\
\text { Roast }\end{array}$ & & & & & & & & 1.00 & $-0.141^{\mathrm{ns}}$ & $0.039^{\mathrm{ns}}$ & $-0.041^{\mathrm{ns}}$ \\
\hline $\begin{array}{l}\text { Quality } \\
\text { Raw (40) } \\
\end{array}$ & & & & & & & & & 1.00 & $0.239^{\mathrm{ns}}$ & $0.682^{* *}$ \\
\hline $\begin{array}{l}\text { Quality Cup } \\
(60)\end{array}$ & & & & & & & & & & 1.00 & $0.874^{* *}$ \\
\hline $\begin{array}{l}\text { Quality } \\
\text { Overall }\end{array}$ & & & & & & & & & & & 1.00 \\
\hline
\end{tabular}

Remark: - **_ Highly Significant, *-Significant and ns-non significant

\section{Summary and Conclusion}

The influence of altitude on caffeine, chlorogenic acid, and nicotinic acid contents was determined on coffee varieties in high, mid and low altitudes. A rapid and validated HPLC-diode array detector method which was accurate, precise and multi-analysis (separation) technique, was used for the simultaneous determination of caffeine, chlorogenic and nicotinic acids that were applicable to four varieties in green and roasted coffee samples. The detection limit was $0.078 \mu \mathrm{g} / \mathrm{mL}$ for nicotinic acid, $0.067 \mu \mathrm{g} / \mathrm{mL}$ for caffeine and $0.088 \mu \mathrm{g} / \mathrm{mL}$ of chlorogenic acid. The result of chemical constituents was chlorogenic acid in coffee variety 7454 on contains lower $(27.17 \pm 0.38 \mathrm{mg} / \mathrm{g})$, in high altitude compared to mid-altitude $(33.85 \pm 2.26 \mathrm{mg} / \mathrm{g})$ and $(39.18 \pm 0.24 \mathrm{mg} / \mathrm{g})$ in low altitude green beans. Similarly coffee variety 7454 higher in nicotinic acid contents $(10.16 \pm 0.75 \mathrm{mg} / \mathrm{g})$ in high altitude compared to $(8.34 \pm 1.57 \mathrm{mg} / \mathrm{g})$ mid-altitude and $(8.25 \pm 0.27 \mathrm{mg} / \mathrm{g})$ low altitude .Coffee variety 7454 contains lower caffeine in high altitude $(13.58 \pm 0.15 \mathrm{mg} / \mathrm{g})$ compared to mid-altitude $(16.07 \pm 0.58 \mathrm{mg} / \mathrm{g})$ and $(19.89 \pm 0.29 \mathrm{mg} / \mathrm{g})$ in low altitude of green coffee beans. The caffeine content of roasted beans coffee varieties 7454 higher $(20.88 \pm 0.14 \mathrm{mg} / \mathrm{g})$ in low altitude compared to mid-altitude $(17.72 \pm 1.46 \mathrm{mg} / \mathrm{g})$ and high altitude $(16.92 \pm 1.38 \mathrm{mg} / \mathrm{g})$. Coffee variety 74110 lower in chlorogenic acid contents $(11.48 \pm 0.46 \mathrm{mg} / \mathrm{g})$ in low altitude compared to mid-altitude $(13.16 \pm 0.44 \mathrm{mg} / \mathrm{g})$ and high altitude $(14.82 \pm 1.51 \mathrm{mg} / \mathrm{g}$.) in roasted beans. Nicotinic acid contents of roasted beans of varieties 7454 higher in high altitude $(8.76 \pm 0.11 \mathrm{mg} / \mathrm{g})$ to compared mid-altitude 
$(7.97 \pm 0.67 \mathrm{mg} / \mathrm{g})$ and low altitude $(6.43 \pm 0.03 \mathrm{mg} / \mathrm{g})$. The highly significant interaction was observed between altitude and coffee varieties in both green and roasted coffee beans on caffeine, chlorogenic and nicotinic acid.As altitude increases caffeine and chlorogenic acid decreases but nicotinic acid increase. The caffeine content in green beans was lower as compared to roasted coffee; significant degradation of chlorogenic acid was observed as goes from green to roasted coffee the same varieties. Chlorogenic acid is thermally unstable and in Arabica coffee the loss of after light roasting and after very dark roasting of beans corresponds to $60.9 \%$ and $96.5 \%$. A strong correlation was observed between cup quality evaluation and these chemical contents and along with altitude. Thus biochemical contents could be used for discriminators coffee for organoleptic quality for coffee varieties and different altitudes.

\section{Reference}

Abu T, (2015) Ethiopia coffee annual Report: global agricultural information network.Retrieved December 21, 2015,fromhtt://gain.usda.gov/recent\%20GAIN\%20publication/Coffee\%20Annual_Addis\%20Ababa_Etiopi a_6-5-2015. Pdf

Abrar S, and Negussie M (2015) Manual for Coffee Quality Laboratory, Ethiopian Institute of Agricultural Research 2015, 7-14

Adnan A, Dieter V, Elke P, and Daniel M (2017) Rapid Prediction of Moisture Content in Intact Green Coffee Beans Using Near-Infrared Spectroscopy Journal of Foods 2017, 6, 38-40.

Agwanda CO, Baradat P, Eskes A, Cilas C, \& Charrier A (2003) Selection for bean and liquor qualities within related hybrids of Arabica coffee in multilocal field trials. Euphytica, 2003, 131(1), 1-14.

Alemayehu DR, (2017) Evaluation of Coffee (Coffea arabica L.) on Raw and Cup Quality Aspect Under the Canopy of Cordia africana and Erythrina Abyssinica Shade Trees Effect in Arsi Golelcha District, Ethiopia 2017, 64 30-43,

Align, A, Sabally K,(2013) Determination of chlorogenic acids (CGA) in coffee beans using HPLC. American Journal of Research Communities, 2013, 1(2):78-91

Alvesl, ST, Dias RCE, Benassi MT (2006) Metodologia papa analisesimultanesa de alcoidonicotinico, trigonelline, acidoclorogenico e cafeinaem café torrado por cromatografialiquida da altiaeffcienta Quim Nova 2006, 29,1164-1168

Anthony F, Combes MC, Astorga C, Bertrand B, Graziosi G, Lashermes P (2002) The origin of cultivated Coffea Arabica L. varieties revealed by AFLP and SSR markers. Theor Appl Genet 2002, 104:894-900

AOAC - Association of Official Analytical Chemists, (1995). Official methods of analysis of AOAC International (16th Ed.) Gaithersburg, MD, USA: AOAC International.

Bekele, YD,(2005) Assessment of cup quality, the morphological, biochemical and molecular diversity of Coffea arabica 1. genotypes of Ethiopia, university of the free state diversity in wild Coffeaarabica $L$. and $C$. canephora P. accessions.Food Chemistry, 2005, 74:423-430.

Bertrand B, Vaast P, Alpizar E, Etienne H, Davrieux, F, \& Charmetant P.(2006) Comparison of bean biochemical composition and beverage quality of Arabica hybrids involving Sudanese-Ethiopian origins with traditional varieties at various elevations in Central America. Tree Physiology, 2006, 26(9), 1239-1248.

Casal S, Oliveira MB, Alves MR, Ferreira MA (2000) Discriminate analysis of roasted coffee varieties for trigonelline, nicotinic acid, and caffeine content. Journal of Agriculture and Food Chemistry 2000, 48:34203424.

Clifford MN, (1985) Chemical and physical aspects of green coffee and coffee products In M. N. Clifford \& K. C. Wilson (Eds.), Coffee: botany, biochemistry and productions of beans and beverage, London:Croom Helm. 1985, 305-374

Davis AP, Gole TW, Baena S, Moat J (2012) The Impact of Climate Change on Indigenous Arabica Coffee (Coffea arabica): Predicting Future Trends and Identifying Priorities. PLoS ONE 2012, 7(11), 479-481.

Decazy F, Avelino J, Guyot B, Perriot J, Pineda, C, \& Cilas C (2003). Quality of different honduran coffees in relation to several environments. Journal of Food Science, 2003, 68(7), 2356-61.

Dry matter and moisture determination (AOAC official method, 1980)

Farah A, Monteiro MC, Calado, V, Franca, AS, \& Trugo, L. C. (2006) Correlation between cup quality and chemical attributes of Brazilian coffee. Food Chemistry, 2006, 98, 373-380.

Giovanni C, Cortese M, Caterina, M, Luigi O, Gianni S, Sauro, V. (2014) Quantification of caffeine, trigonelline and nicotinic acid in espresso coffee: the influence of espresso machines and coffee cultivars. International Journal of Food Science and Nutrition, 2014, 65(4):465-469.4

ICO (International coffee organization) (2013) Production statistics: http//www.ico.org/production_statiscts .ASP

Jo“et, Laffargue, A, Descroix, F, Doulbeau, S, Bertrand, B, de kochko A, \& Dussert, S. (2010) Influence of environmental factors, wet processing and their interactions on the biochemical composition of green Arabica coffee beans. Food Chemistry, 2010, 118, 693-701.

Kassaye T, Dheer J, Duchateau L, Boeck, P (2016) Prediction of specialty coffee cup quality based on near-infrared 
spectra of green coffee beans. Talanta. 2016, 150:367-374

Kathurima C, W, Kenji G M, Muhoho, SM, Boulanger R, \& Davrieux, F (2010) Discrimination of Coffeaarabica Hybrids of the Composite Cultivar Ruiru 11 by Sensorial Evaluation and Biochemical Characterization. Advance Journal of Food Science and Technology, 2010, 2(3), 148-154

Ky CL, Louarn J, Guyot B., Dussert S, Hamon S \& Noirot M. (2001) Caffeine, trigonelline, chlorogenic acids and sucrose diversity in wild coffee Arabica and Canephora accessions. Food Chemistry, 2001, 75, 223-230.

Lashermesl P, Combesl MC, Toparf P, Graziose G, Bertrand B, Anthony F (2010) Molecular Breeding In Coffee (Coffea Arabic A L.) Coffee Biotechnology and Quality 101-112

Leroy T Ribeyre F, Bertrand B, Charmetant P, Dufour M, Montagnon C (2006) Genetics of coffee quality. Brazilian Journal of Plant Physiology, 2006, 18(1), 229-242.

Meyer FG, (1965) Notes on wild Coffea arabica from Southwestern Ethiopia, with some historical considerations. Economic Botany 1965, 19, 136-151

Montagnon C, Guyot B, Cilas C, \& Leroy, T. (1998) Genetic parameters of several biochemical compounds from green coffee, Coffea canephora. Plant Breeding, 1998, 117, 576-578.

Morais H, Caramori P, Ribeiro AM, Gomes JC and Koguishi MS. (2006) Microclimatic characterization and productivity of coffee plants grown under shade of pigeon pea in Southern Brazil. Pesq. Agropec. Bras. 2006, 41:5. 763-770.

Muschler RG, (2001). Shade improves coffee quality in a sub-optimal coffee-zone of Costa Rica Agroforestry Systems 2001, 85: 131-139,

Natalina C, António E, José R, Nuno De Alvarenga and Fernando L (2013) Identification of Chemical Clusters Discriminators of Arabica and Robusta Green Coffee. International Journal of Food Properties, 16:895-904, 2013 Taylor \& Francis Group.

Navarra G, Moschetti M, Guarrasi V, Mangione M, Militello V. and LeoneM (2017) Simultaneous Determination of Caffeine and Chlorogenic Acids in Green Coffee by UV/Vis Spectroscopy Journal of Chemistry .2017, 1 $1-9$

Sultan, A, Mekonnen N, and Degefa M (2014) Hybrid coffee (Coffea arabicaL) genotypes quality evaluation under the different environment of Southern Ethiopia Greener Journal of Agriculture Science. 2014, 4 (6), 245-251

Sunarharum WB, Yuwono SS, Pangestu NBSW, and Nadhiroh H (2018) Physical and sensory quality of Java Arabica green coffee beans International Conference on Green Agro-industry and Bio-economy IOP Conf. Series: Earth and Environmental Science 2018, 131 01-04

Tessema A, Alamerew S, Kufa, T, \& Garedew W (2011) Variability and Association of Quality and Biochemical Attributes in Some Promising Coffea Arabica Germplasm Collections in Southwestern Ethiopia. International Journal of Plant Breeding and Genetics, 2011, 5, 302-316.

Vieira RD, Tekrony DM, Egli DB \& Rucker M (2001) Electrical conductivity of soybean seeds after storage in several environments. Seed Science \& Technology, 2001, 29, 599-608

Walyaro DJA (1983) Considerations in breeding for improved yield and quality in arabica coffee (Coffea arabica L.) $1983,22-30$ 